\title{
Espiritualidade nas organizações: um estudo bibliométrico dos principais sites de buscas acadêmicas do Brasil
}

Spirituality in organizations: a bibliometric study of the main Brazilian academic search engines

Ivo Pedro Gonzalez Junior ${ }^{a}{ }^{*}$, Daniel Ricardo da Silva ${ }^{b}$ (i), Natannael Saraiva P. da Cruz ${ }^{c}$ (i) ${ }^{a, b, c}$ Faculdade Adventista da Bahia, Cachoeira-BA, Brasil

\section{Resumo}

Existe a influência da espiritualidade nas organizações, sendo este assunto mais amplamente abordado em países desenvolvidos, O presente artigo pretende analisar através de estudo bibliométrico o que já foi escrito até o presente momento em língua portuguesa sobre espiritualidade nas organizações, mapeando as publicações devido ao crescente interesse por os positivos resultados alcançados em produtividade e satisfação no ambiente de trabalho. Foram realizadas buscas em quinze dos principais sites de buscas de artigos acadêmicos utilizados no Brasil com as palavras chave "Espiritualidade nas organizações" dos quais foram encontrados conteúdo útil para a pesquisa atual em apenas cinco deles, que são: BDTD, EDUCATIONAL ADMINISTRATION ABSTRATIC, GOOGLE ACADEMIC, SPELL e SCIELO. Extraindo sessenta e nove (69) artigos analisados no período de 10 anos (20052015). Para tanto foi utilizado o estudo bibliométrico para as referidas analises quantitativas. Ao mesmo tempo em que se vê a importância do assunto nas mais diversas esferas organizacionais ainda há pouco estudo sobre o assunto em língua portuguesa, menos ainda pesquisas empíricas sobre o assunto. Fica claro que o devido tema está nos holofotes de pesquisadores do Brasil, e é fundamental que se produza artigos nesta perspectiva teóricometológico.

Palavras chave: Espiritualidade; bibliométrico; organizações

\begin{abstract}
The influence of spirituality in organizations is widely known, a subject more widely covered in developed countries. However, searches were done on fifteen of the main search sites of academic articles used in Brazil with the keywords "Spirituality in organizations" from which
\end{abstract}

\footnotetext{
* Autor de correspondencia:

Tel.: +55 75 9186-0403

E-mail: ivo.junior@adventista.edu.br

DOI: https://doi.org/10.17162/riva.v8i1.1628

Recibido: 10/07/2019 Aceptado: 13/09/2021
} 
content was found Useful for current research in just five of them, which are: BDTD, EDUCATIONAL ABSTRACT ADMINISTRATION, GOOGLE ACADEMIC, SPELL and SCIELO. Extracting sixty-nine (69) articles analyzed in the period of 10 years (2005-2015). For that, a bibliometric study was used for these quantitative analyzes. At the same time that the importance of the subject is seen in the most diverse organizational spheres there is still little study on the subject in Portuguese language, still less empirical research on the subject. This article intends to analyze through bibliometric study what has been written so far in Portuguese on spirituality in organizations mapping the publications due to the growing interest in the positive results achieved in productivity and satisfaction in the work environment. It is clear that the proper theme is in the spotlight of Brazilian researchers, and it is fundamental that articles are produced in this theoretical-methodological perspective.

Keywords: Spirituality; Bibliometric; Organizations

\section{Introdução}

O presente estudo visa explorar o arcabouço literário sobre Espiritualidade nas Organizações, para tanto foram analisados os bancos de dados: da Biblioteca Brasileira Digital de Teses e Dissertações - BDTD, Educational Administration Abstratic, Google Academic, Scientific Periodicals Electronic Library - SPELL, Scientific Eletctronic Library Online - SCIELO. Entender e compreender como a utilização deste viés cientifico oportuniza o ganho de benefícios para as organizações é a discussão que perpassa o estudo, haja vista que é um assunto multidisciplinar.

À medida que a sociedade cresce, a necessidade de um ambiente propicio para as pessoas viverem em comunidade, de igual forma no âmbito organizacional em que as empresas vão ganhando espaço de tal forma que as pessoas passem parte do tempo no trabalho, as mesmas precisam desenvolver um aporte que traga o reconhecimento de que os empregados têm uma vida interior que alimenta, e é alimentada, pela realização de trabalho com significado num contexto de comunidade (Ashmos \& Duchon, 2000).

O tema espiritualidade nas organizações vem crescendo devido ao interesse no estudo cientifico pautado no desenvolvimento dos aspectos motivadores da própria gestão de pessoas que viabiliza a importância de uma empresa ter a responsabilidade social para com seus colaboradores, evitando dessa forma o desenvolvimento de doenças psicossomáticas devido ao isolamento e/ou vida sem propósito, haja vista que, a adoção da abordagem traz ganho em produtividade para a empresa. Para o indexação do trabalho foi adotado o estudo bibliométrico e extraído da plataforma web de 5 (cinco) dos principais sites de buscas acadêmicas do Brasil, descritos acima, sessenta e nove (69) artigos publicados que foram 
utilizados para as análises quantitativas do respectivo assunto com o objetivo de classificar Ihes devidamente fazendo um mapeamento referindo à dez anos.

O presente estudo está articulado sobre o que há em língua portuguesa em banco de dados, incluindo uma revisão da literatura da espiritualidade no ambiente de trabalho. Mais adiante são apresentados os procedimentos metodológicos e analisados os resultados obtidos deste estudo bibliométrico, as considerações finais e suas referências.

\section{Revisão da Literatura}

Trabalhar é sem dúvida uma dádiva ao ser humano, é também um constante aprendizado além de proporcionar atividade física e mental, auto sustento, convívio em sociedade e aperfeiçoamento das habilidades, proporcionando senso de valor diante da sociedade e trazendo autoestima, mesmo nas atividades de trabalhos mais simples é possível encontrar pessoas felizes e realizadas, assim como nos escalões mais elevados do poder, encontram-se grandes executivos perdidos em suas próprias existências.

Devido à crescente demanda tecnológica e os afunilamentos nas especialidades de trabalho, cada vez mais os profissionais ficam mais profissionais, e menos pessoais, em casa, com os amigos e até mesmo na vida religiosa, no entanto tentam preencher este vazio espiritualizando o trabalho (Menegat, Sarmento, \& Díaz, 2014). Buscam ainda preenchimento em áreas específicas como sugere (Tecchio, 2015) senso de comunidade, trabalho com significado e vida interior.

Segundo Zohar e Marshall (2002), a espiritualidade faz parte da inteligência do ser humano, seria natural que o interesse pelo tema enveredasse para a área organizacional. $\mathrm{A}$ espiritualidade começou a fazer parte das organizações em meados dos anos 90 . A ideia do sentido da vida aparece como tema principal de algumas palestras do Papa João Paulo II (Vaticano, 2006) para ele, ética e sentido da vida estão intimamente ligados. A responsabilidade ao mesmo tempo pessoal pela própria vida, e social - pela justiça, pela paz e pela ordem moral do próprio ambiente e da sociedade caracterizam o homem que tem consciência do sentido da vida.

Conforme Gardner (1999), a inteligência espiritual também pode ser chamada existencial ou transcendente e a define como: A capacidade para situar-se a si mesmo em relação ao cosmos, em relação a si mesmo e em relação as características existenciais da condição humana, quais sejam o significado da vida, o significado da morte e o destino final do mundo físico e psicológico em experiências profundas como o amor a outra pessoa ou imersão em um trabalho de arte. (Roselló, 2012) 
Já (Roselló, 2012) aponta a capacidade de compreender e de ser espiritual como inteligência espiritual, e a define como a capacidade que abarca a transcendência humana, o sentido do sagrado e os comportamentos virtuosos. Relaciona-a diretamente com a experiência religiosa e ética. Segundo Rabello (2008) já transcendência pode ser definida como a capacidade de entender uma experiência a priori nunca vivida ou experimentada.

A inteligência espiritual é uma característica do ser humano, que o capacita a pensar e agir regido por uma energia espiritual, que difere da experiência comum de nossa natureza física. Vários autores mesclam os conceitos de religiosidade como espiritualidade, todavia tais são muito distintos haja vista que a religiosidade é mais precisamente definida por: crença na existência de uma força ou forças sobrenaturais, considerada(s) como criadora(s) do Universo... Qualquer filiação a um sistema específico de pensamento ou crença que envolve uma posição filosófica, ética, metafísica, etc. (Ferreira, 2004).

De modo geral a organização ou empresa é vista como um sistema socioespiritual. Sendo que, vista desta maneira porque é um sistema interligado tendo como principal recurso o capital humano, por isso faz-se necessários criar um ambiente moral e social para tanto vários seminários, workshops treinamentos e palestras têm sido realizados para gestores a fim de tornar não apenas a vida pessoal, como também a organização em um ambiente autodesenvolvido, com pessoas autorrealizadas libertas de pensamentos negativos. (Barreto, Thompson, \& Feitosa, 2011).

\subsection{Espiritualidade no ambiente de trabalho (EAT)}

O estudo sobre a Espiritualidade no Ambiente de Trabalho (EAT) foi pouco difundido até início do século XXI, ganhando mais espaço em debates organizacionais devido aos ganhos ascendentes em produtividade e satisfação do trabalhador, à medida que logram resultados vitais encontram oportunidades nas organizações para realizar trabalho com significado, no contexto de uma comunidade, com um sentido de alegria e de respeito pela vida interior (Rego, Cunha, \& Souto, 2007). Ressalta ainda que pessoas espiritualizadas tem melhor qualidade de vida, forte senso de pertença, mais alto nível de resiliência, menos trauma por estresse, vida mais satisfatória, equilíbrio na frequência cardíaca, menores índices de comportamento depressivo e menos propensão a patologias infecciosas.

Para tanto há a necessidade de criar um ambiente adequado ao bom desenvolvimento em todos os aspectos, fatores que podem ser aprendidos. De acordo com Senge (2009) os aspectos ligados a aprendizagem em equipe considera que, um ambiente adequado incentiva a participação de todos, ou seja, a soma das partes formam um todo, neste interim a espiritualidade dentro das organizações fomenta o desenvolvimento de um ciclo vivo, que 
salienta a busca de equilíbrio emocional no momento de decisões importantes das instituições.

Mais ainda, a inteligência espiritual segundo Roselló (2012) corrobora a inteligência emocional e a lógico-racional, habilitando-a a transcender o sofrimento, gerando valor. Permite que cada área cerebral especializada realize suas atividades formando um todo funcional, a mesma é para a empresa o que é a vitamina "C" para o sistema imunológico humano, catalisando os outros nutrientes a fim de equilibrar o organismo. Deste modo a empresa ganha conotações e jargões como os seres vivos, como: Crescimento empresarial (Ribeiro, 2012), empresas como organismo vivo (Fernández, 2016), biologia do aprendizado empresarial (Pereira \& Borges, 2006), empresa verde (Layrargues, 1998), empresa viva (Woods \& Cortada, 2000), ecologia espiritual (Araújo \& Azevedo, 2011).

Alguns estudiosos das organizações, no entanto, argumentam que a espiritualidade organizacional pode se converter em um discurso com o intuito de manipular as pessoas com objetivos puramente materialistas (Vergara \& Moura, 2010). A ainda quem afirme que o homem atribui poderes divinos a tudo aquilo que é de difícil compreensão (Kerber, 2009), o que em casos específicos pode confundir sobre conceitos de coisas tais como, sagradas, divino, Deus, e até gerar conflitos, sobre as origens, entre os mais diversos.

Segundo Enes \& Costa (2015) apud Marcos (2010), citam que a espiritualidade no ambiente de trabalho é uma experiência inter-relacionada entre os membros de uma mesma organização de trabalho, fortalecida pela boa vontade individual. Esta leva a criação adjunta de uma cultura organizacional, sintetizada pela reciprocidade e solidariedade, sendo assim o resultado será melhor engajamento, no trabalho.

Já para Neal (apud Boog, 2005, p. 1) ressalta que "se qualquer organização quiser viver, terá que promover radicais, transformações em si mesmas. Essas não se referem à estrutura, más sim aos valores, essencialmente aos valores do coração e da alma" ou como possa chamar princípios norteadores da vida e da existência do ser humano, "ou seja, um líder espiritual é uma pessoa de ações compatíveis com seus valores. Em virtude disso podemos dizer que uma pessoa ou organização não podem "enganar" ou "fingir" serem espirituais, pois suas ações precisam exalar espiritualidade" (Barreto, Thompson, \& Feitosa, 2010).

Apoiar as estratégias organizacionais que incentivam a espiritualidade no local de trabalho, podem trazer benefícios que são expressos no desempenho organizacional do funcionário, como honestidade, criatividade, confiança, senso de realização pessoal e compromisso pessoal (Garcia, 2013; Krishnakumar \& Neck, 2002). 


\section{Metodologia da pesquisa}

Com o intuito de tornar mais claro e didático o presente estudo foi realizado uma busca e transformado em bibliometria artigos extraídos de cinco (5) dos dezessete (17), principais sites de buscas acadêmicas no Brasil, como segue a lista: BDTD, EDUCATIONAL ADMINISTRATION ABSTRATIC, GOOGLE ACADEMIC, SPELL e SCIELO. Para tanto foram utilizadas as palavras chaves "Espiritualidade nas organizações", foram utilizados como critério de inclusão os artigos em língua portuguesa que continha em seus respectivos títulos às frases que fizessem ligação direta com a área da gestora independente da natureza da organização, no entanto foram excluídos os artigos que tratassem apenas sobre o bem estar, ou apenas sobre a recuperação de pacientes, sobre profissionais de saúde em geral que não fosse diretamente relacionado á equipe gestora.

Dentre os artigos selecionados para o presente estudo bibliométrico e tratados com ferramentas estatísticas em Excel de forma quantitativa, por se tratar de um tema novo em especial para Brasil e principalmente no âmbito administrativo. Os artigos analisados foram incluídos todos que contêm as características mencionadas no parágrafo anterior, sendo que as primeiras publicações datam de 2005 e as últimas de 2015.

Alguns autores motivados por razões desconhecidas avançaram em suas publicações sem mencionar data de publicação, outros ainda de universidades específicas tanto nacionais como estrangeiras de língua portuguesa não deixaram claros os métodos e/ou instrumentos de pesquisa assim como os objetivos ou modelos utilizados, tão pouco seus modelos de abordagem, no entanto vários deles mostram-se bem objetivos e sucintos no que propunham estudar dentre eles destacam-se os artigos menores, observa-se ainda que os artigos maiores nem sempre tratam-se de riqueza de detalhes, mas de riqueza de diálogo ou muitas palavras para atingir os mesmos fins.

Com as características atribuídas ao presente estudo foram selecionados sessenta e nove (69) artigos e lidos seus resumos e referenciais teóricos e ainda a introdução na ausência deste, em outros casos para maior profundidade ou para encontrar detalhes não especificados com clareza foi avançada a leitura para o interior dos artigos.

Dentre os cinco sites utilizados na pesquisa o mais rico em quantidade de publicações sobre o tema encontra-se o GOOGLE ACADEMIC com sessenta e quatro publicações úteis, de onde pode-se extrair conteúdo para a confecção de tabelas sobre: fontes de busca em seus respectivos anos de publicações, número de autores por artigo, natureza do objetivo, instrumentos de pesquisa, quantidade total de buscas feitas, temas adotados por cada autor, método, e por fim o nome de cada um dos outros sites buscas onde não foram encontrados conteúdos para este estudo. 


\section{Resultados}

No presente estudo bibliométrico foram verificados no intervalo de dez anos, ou seja, período que abrange de 2005-2015, 69 artigos sobre o tema "espiritualidade nas organizações" entre os principais sites de buscas acadêmicas Brasileiras: BDTD, EDUCATIONAL ADMINISTRATION ABSTRATIC, GOOGLE ACADEMIC, SPELL e SCIELO, entre os 13.417 conforme tabela 5 , foram selecionados apenas 69 artigos o equivalente a $0,51 \%$ do total de artigos publicados. O método bibliométrico buscou analisar o quantitativo de autores, total de artigos publicados, natureza do objetivo, instrumento de pesquisa, publicações do tema, método de pesquisa e outros sites pesquisados.

Mencione todos los resultados incluso aquellos que no esperaba obtener; es decir, no oculte aquellas significaciones pequeñas o valores no significantes por más incómodos que resulten, no incluya datos individuales a no ser que sea un estudio de caso único, en su lugar organice los datos en forma global. No revise conceptos y procedimientos básicos ni proporcione citas para los procedimientos estadísticos de uso común. Puede reportar los datos faltantes y describa los métodos para abordar los datos faltantes en el caso de que se haya usado (como imputación múltiple).

\section{Tabela 1}

Total de artigos publicados em 5 dos principais sites de busca acadêmica do Brasil (2005 a 2015)

\begin{tabular}{cccccccc}
\hline Ano & $\begin{array}{c}\text { Google } \\
\text { academic }\end{array}$ & Edtd & $\begin{array}{c}\text { Educational } \\
\text { administration } \\
\text { abstratic }\end{array}$ & Spell & Scielo & Total \\
\hline 2005 & 1 & - & - & - & - & 1 \\
2006 & 1 & - & - & - & - & 1 \\
2007 & 2 & - & 1 & - & 1 & 4 \\
2008 & 1 & 1 & - & - & 1 & 3 \\
2009 & 5 & 1 & - & - & 1 & 7 \\
2010 & 4 & 1 & - & - & - & 5 \\
2011 & 8 & - & 1 & - & - & 9 \\
2012 & 7 & - & - & - & - & 7 \\
2013 & 4 & - & 1 & - & - & 5 \\
2014 & 10 & 1 & - & 1 & - & 12 \\
2015 & 8 & 1 & - & - & 1 & 10 \\
Válido & & & & - & - & - & 5 \\
Não & 5 & - & & & & \\
\hline
\end{tabular}




\begin{tabular}{ccccccc} 
Total & 56 & 5 & 3 & 1 & 4 & 69 \\
$\%$ & $\mathbf{8 1 , 1 6}$ & $\mathbf{7 , 2 5}$ & $\mathbf{4 , 3 5}$ & $\mathbf{1 , 4 5}$ & $\mathbf{5 , 8 0}$ & $\mathbf{1 0 0 , 0 0}$ \\
\hline
\end{tabular}

Fonte: Dados da pesquisa

Verifica-se que os anos mais produtivos no assunto em questão foram os dois últimos analisados (2014 e 2015) somando-se 22 artigos o equivalente á $31,88 \%$, sendo que o quantitativo maior de artigos publicados encontra-se no site GOOGLE ACADÊMIC com 56 artigos equivalente á $81,16 \%$, percebe-se que os autores tem tido mais preferência nesta plataforma web, ao mesmo tempo que, plataformas como ESPELL $(1,45 \%)$ e EDUCATIONAL ADMINISTRATION ABSTRATIC (4,35\%)2 tem sido menos utilizadas para as publicações no tema (EAT).

\section{Tabela 2}

Número de autores por artigo

\begin{tabular}{ccccc}
\hline $\begin{array}{c}\text { Quantidade de } \\
\text { autores }\end{array}$ & Frequência & Porcentual & Porcentagem válida & $\begin{array}{c}\text { Porcentagem } \\
\text { acumulativa }\end{array}$ \\
\hline 1 & 33 & 47,83 & 47,83 & 47,83 \\
2 & 15 & 21,74 & 21,74 & 69,57 \\
3 & 15 & 21,74 & 21,74 & 91,30 \\
4 & 4 & 5,80 & 5,80 & 97,10 \\
5 & 2 & 2,90 & 2,90 & 100,00 \\
TOTAL & 69 & 100 & 100 & \\
\hline
\end{tabular}

Fonte: Dados da pesquisa

Nota-se que na tabela 2, o número de publicações nas plataformas web quantificado apenas um autor por artigo é equivalente a 47,83 que de longe é a maior frequência de publicações sobre o determinado tema a de se destacar que a soma de artigos publicados com apenas um autor é superior à somatória de publicações com 2(dois), 3 (três) e 5 (cinco). Possivelmente por ser um assunto novo no ambiente acadêmico. Enquanto que o número de 2 e 3 autores por artigo são na mesma proporção de 21,74\% e 4 autores com 5,80\%. Porém com 5 autores temos apenas um pequeno porcentual de 2,90\%.

O gráfico 1 nos traz a visualização da natureza dos objetivos quanto a investigação que os autores propuseram nas publicações dos seus respectivos artigos. De um modo geral utilizamos o gráfico para analisar a porcentagem dos artigos dentro de uma perspectiva bibliométrica a qual identificamos e evidenciamos que a taxa de $52,17 \%$ das publicações não foram encontradas a sua devida "Natureza do Objetivo", dentre os motivos destacam-se artigos que foram transformados em livros, outros postados em revistas especificas no intuito de reduzir o conteúdo ou fim de alinhar aos padrões estabelecidos, excluiu-se a natureza do 
objetivo. Sendo que a descritiva angarie-a 26,09\% dos artigos publicados nas 5 (cinco) plataformas descritas.

\section{Gráfico 1}

Natureza de objetivo

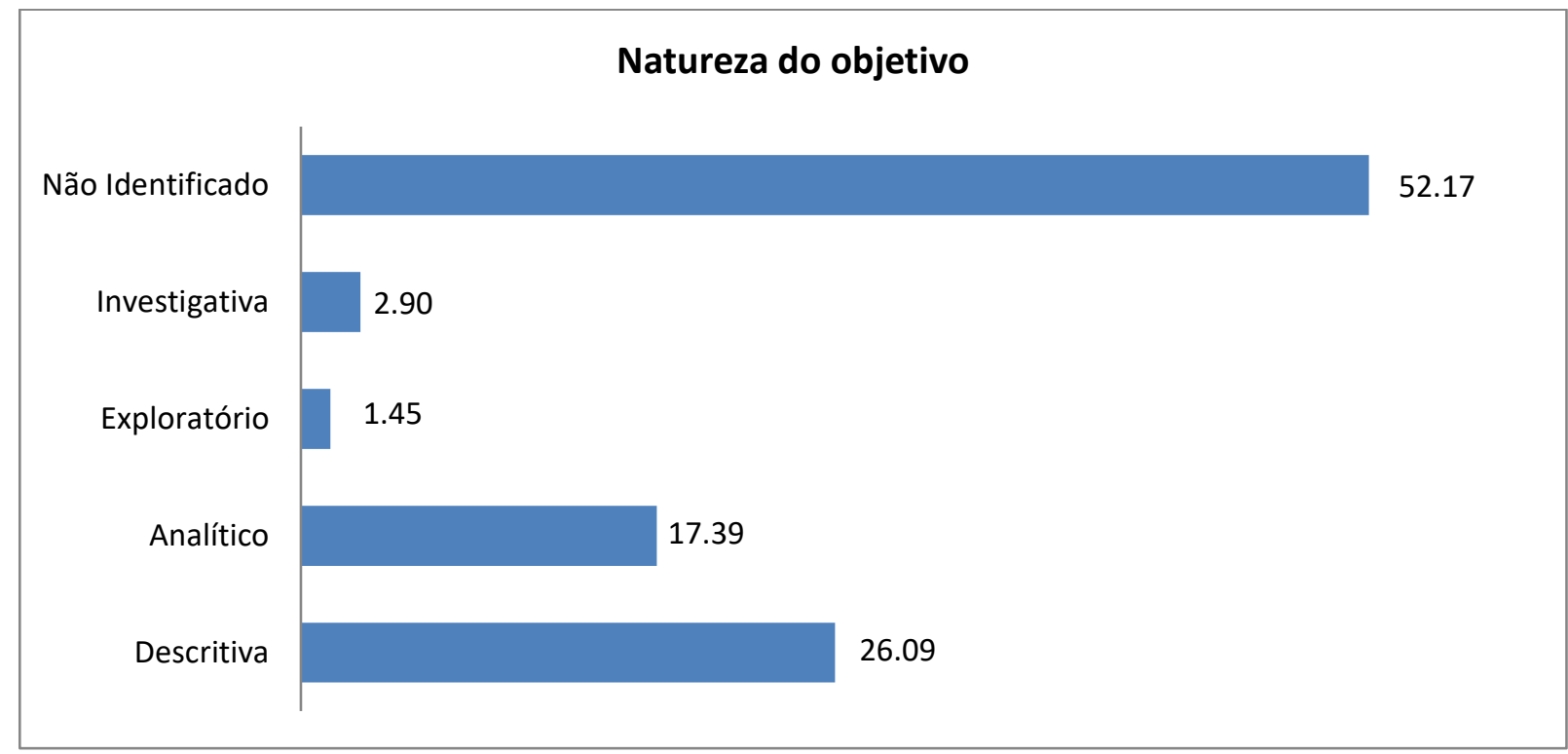

Fonte: Dados da pesquisa

Percebe-se que no estudo bibliométrico as análises de caráter exploratório são encontradas taxa de 1,45\%, enquanto a analítica corresponde ao número de $17,39 \%$ dos artigos publicados nos sites pesquisados.

Observa-se correlação entre os itens de natureza do objetivo e os instrumentos de pesquisa, onde os números mais se alinharam, neste último caso (instrumentos de pesquisa, apresentado no gráfico 2) não identificados alcançaram o patamar de 47,83\%, seguido por questionário 24,64\%, entre os menores índices se igualam em 1,45\% os: questionário/entrevista/observação, pesquisa indutiva, pesquisa biliog./questionário, entrevista/questionário e entrevista/observação. Se considerarmos as outras análises onde utilizaram mais de um instrumento de pesquisa onde incluem questionário encontra-se um total de $28,99 \%$ contra $23,27 \%$ dos instrumentos identificados e não incluem questionário. Ressalta-se a bibliometria com 4,35\% sendo considerado um número plausível por si tratar de uma análise das publicações já existentes.

\section{Gráfico 2}

Instrumentos de Pesquisa 


\section{INSTRUMENTOS DE PESQUISA}

Questionário/ Entrevista/ Observação

QUESTIONÁRIO

1.45

PESQUISA INDUTIVA

PESQUISA BIBLIOGRÁFICA

PESQ. BIBLIOG. / QUESTIONÁRIO

NÃO IDENTIFICADO

ENTREVISTAS/QUESTIONARIOS

ENTREVISTAS/ANÁLIZE DOCUMENTAL

Entrevista/ Observação

ENTREVISTA

BIBLIOMETRIA

ANALIZE DOCUMENTAL

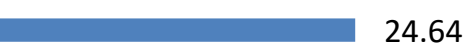

1.45

4.35

1.45

1.45

5.80

1.45

2.90

4.35

2.90

Fonte: Dados da pesquisa

Dentro do intervalo de (2005-2015), foram publicados no site GOOGLE ACADEMIC 13.400 artigos relacionados a tema proposto, e nos outros como SPELL (1 artigo), SCIELO (5 artigos) e EDUCATIONAL ADMINISTRATION ABSTRATIC (3 artigos). Vale salientar que de um total de 13.417 publicações um site se destaca mais devido à preferência por ser uma plataforma web mais conhecida.

\section{Tabela 3}

De publicações do tema no intervalo (2005-2015)

\begin{tabular}{lcccc}
\hline \multicolumn{1}{c}{ Site } & $\begin{array}{c}\text { Frequência de } \\
\text { artigos sobre } \\
\text { todos os temas }\end{array}$ & Porcentual & $\begin{array}{c}\text { Porcentagem } \\
\text { válida }\end{array}$ & $\begin{array}{c}\text { Porcentagem } \\
\text { acumulativa }\end{array}$ \\
\hline Google academic & 13.400 & 99,87 & 99,87 & 99,87 \\
Edtd & 8 & 0,06 & 0,06 & 99,93 \\
Educational & 3 & 0,02 & 0,02 & 99,96 \\
$\begin{array}{l}\text { administration } \\
\text { abstratic }\end{array}$ & 1 & 0,01 & 0,01 & 99,96 \\
$\begin{array}{l}\text { Spell } \\
\text { Scielo }\end{array}$ & 5 & 0,04 & 0,04 & 100,00 \\
Total & 13417 & 100 & 100 & \\
\hline
\end{tabular}

Fonte: Dados da pesquisa 
Quando se faz uma simples busca nos sites mencionados acima incluindo todos os anos de suas publicações, rapidamente encontramos 13417 unidades de conteúdo, logo, destes apenas $0,51 \%$ tem verdadeira relevância para a área organizacional no que diz respeito ao objetivo proposto, destes apenas $0,02 \%$ são bibliometria, sendo que praticamente todo o material já escrito sobre o assunto menciona vantagens e benefícios da EAT, para tanto o presente artigo faz-se de extrema relevância para quem quer entender de forma mais abrangente a EAT como esta se encaixa em suas intenções e estratégias.

$\mathrm{Na}$ tabela 4, são analisados a luz do conhecimento empírico a diversidade de temas que seguem a mesma lógica do atual estudado. A grosso modo um grande contingente de organizações preferem tratar do assunto com uma visão holística e não especificamente, haja vista que o universo da pesquisa bibliométrica utilizou-se um total de 69 artigos, a saber $82,61 \%$ dos trabalhos são referentes a EAT.

\section{Tabela 4}

Sobre o tema adotado

\begin{tabular}{lcccc}
\hline & Frequência & Porcentual & $\begin{array}{c}\text { Porcentagem } \\
\text { válida }\end{array}$ & $\begin{array}{c}\text { Porcentagem } \\
\text { acumulativa }\end{array}$ \\
\hline $\begin{array}{l}\text { Caridade/ } \\
\text { espiritualidade }\end{array}$ & 1 & 1,45 & 1,45 & 1,45 \\
$\begin{array}{l}\text { Comunicação, saúde, } \\
\text { educação. }\end{array}$ & 1 & 1,45 & 1,45 & 2,90 \\
Comunicação & 1 & 1,45 & 1,45 & 4,35 \\
Empreendedorismo & 1 & 1,45 & 1,45 & 5,80 \\
$\begin{array}{l}\text { Esp. Nas organ. } \\
\text { Gestão de pessoas }\end{array}$ & 57 & 82,61 & 82,61 & 88,41 \\
Gestão estratégica e & 4 & 5,80 & 5,80 & 94,20 \\
organizacional & 1 & 1,45 & 1,45 & 95,65 \\
Liderança espiritual & 1 & 1,45 & 1,45 & 97,10 \\
Qualidade de vida no & 2 & 2,90 & 2,90 & 100,00 \\
trab. & 69 & 100,00 & 100,00 & \\
Total & & & & \\
\hline
\end{tabular}

Fonte: Dados da pesquisa

No entanto, outros temas que correlacionam com o estudado são apresentados na tabela como: Caridade e espiritualidade, comunicação, saúde, educação, comunicação, empreendedorismo, gestão de pessoas, gestão estratégica e organizacional, liderança espiritual, qualidade de vida no trabalho. Tratam do mesmo assunto, mas com uma perspectiva diferenciada da que utilizamos por que não é especifica. 


\section{Tabela 5}

Método de pesquisa

\begin{tabular}{lcccccc}
\hline \multicolumn{1}{c}{ Método } & $\begin{array}{c}\text { Google } \\
\text { academic }\end{array}$ & Edtd & $\begin{array}{c}\text { Educational } \\
\text { administration } \\
\text { abstratic }\end{array}$ & Spell & Scielo & Total \\
\hline Análise heurística & 1 & - & - & - & - & 1 \\
Análise fatorial & 1 & - & - & - & - & 1 \\
Ensaio teórico & 2 & - & - & - & - & 2 \\
Estudo de caso & 2 & - & 1 & 1 & - & 4 \\
Não identificado & 26 & 4 & - & & 1 & 31 \\
Pesquisa bibliográfica & 13 & - & - & - & - & 13 \\
Quantitativa/qualitativa & 1 & - & - & - & - & 1 \\
Revisão bibliográfica & 1 & - & - & - & - & 1 \\
Survey & 9 & 1 & 2 & - & 3 & 15 \\
Total & 56 & 5 & 3 & 1 & 4 & 69 \\
\hline
\end{tabular}

Fonte: Dados da pesquisa

Quanto ao método empregado na pesquisa, entende-se que a forma em que foram abordados os artigos, 4 (quatro) deles aparecem apenas uma vez nos resultados, como segue: Análise heurística, Análise fatorial, Quantitativa/qualitativa, Revisão bibliográfica e o Ensaio teórico aparece 2 (duas) vezes.

Vale ressaltar que o método da pesquisa bibliográfica e Survey são mais expressivos com um total de 28 artigos. Em contrapartida foram verificados que 31 artigos não têm uma clareza quanto a sua identificação de método proposto.

Foram realizadas buscas em outros 12 (doze) sites acadêmicos como apresentado na tabela 6 , os quais não constaram nenhum artigo com as características atribuídas ao presente estudo no período que contemple 2005 - 2015. Outros sites entre os que foram encontrados conteúdos úteis, não permitiam acesso (visualizar ou baixar) ao conteúdo.

\section{Tabela 6}

Outros sites pesquisados

\begin{tabular}{ll}
\hline Academic search elite & Artigo não encontrado \\
\hline Atla & Artigo não encontrado \\
\hline Public administration abstracts & Artigo não encontrado \\
\hline Biblioteca nacional digital brasil & Artigo não encontrado \\
\hline Eric & Artigo não encontrado \\
\hline Bvs ondontoligia & Artigo não encontrado \\
\hline Pepsic & Artigo não encontrado \\
\hline
\end{tabular}


Bio med central

Artigo não encontrado

Portal dominio publico

Artigo não encontrado

World library of science

Artigo não encontrado

Pedro

Artigo não encontrado

Bvs psicologia

Artigo não encontrado

Fonte: Dados da pesquisa

\section{Considerações Finais}

Em suma, o estudo proposto buscou analisar e indexar as publicações no intervalo de 10 anos (2005-2015), em 5 (cinco) dos principais sites de publicações acadêmicas do Brasil. Deste modo, verifica-se que embora seja um tema novo na área empresarial, ou mais ainda em língua portuguesa e com mais raridade no Brasil, considerando que vários dos artigos apresentados são de origem Portuguesa (universidade de Lisboa). Vale salientar que conforme a tabela 1, no ano de 2014 a uma crescente produção de conteúdos sobre EAT no cenário acadêmico em relação aos outros anos.

No prisma do âmbito organizacional, o presente estudo bibliométrico corrobora para a absorção do tema EAT como estratégia unida ao planejamento, a fim de atingir os objetivos propostos. Nessa direção, os estudos sobre o determinado tema visualizam com base nos artigos analisados conclui-se que a espiritualidade é um fator intrínseco do ser humano, considerada também como uma inteligência, como a capacidade de unir todas as demais inteligências e que ao mesmo tempo a religiosidade nada menos interpõe que exercitar a espiritualidade através dos costumes, culturas e rituais.

Considerando o fato de haverem tantos temas diferentes abordando a espiritualidade dentro do contesto organizacional (como apresentado na tabela 4) compreende-se o a conclusão de alguns autores em que a inteligência espiritual é o que une todas as outras capacidades, para tanto, as organizações que incluírem valores espirituais em seu cotidiano terão uma equipe mais engajada no mundo coorporativo tendo em mente cada stakehoder de forma individual o que consequentemente trará resultados mais duradouros.

O presente estudo limita-se á análises sobre publicações específicas da espiritualidade nas organizações, no entanto não inclui analisar os gestores das organizações tidas como espirituais se eles mesmos o são, se a vida pessoal dos gestores interfere na espiritualidade do ambiente de trabalho de uma forma mais abrangente, e como isto afeta a implantação de projetos focados na espiritualidade da organização que estão inseridos.

Sugerem-se também futuras pesquisas sobre as quantificações de produtividade das empresas espirituais, assim como os índices de satisfação dos trabalhadores, mas também se devam incluir estudos de caso sobre a espiritualidade como diferencial competitivo. Possivelmente o que seja inovadoramente radical sobre análises científicas á entrar em 
contato com os autores dos trabalhos publicados, pois haja vista que seja coerente dedicarse tanto tempo no estudo de determinado assunto e estar também buscando algo superior.

\section{Referencias}

Araújo, I. F., \& Azevedo, C. A. (2011). Ensaio Teórico sobre a Influência da Espiritualidade na Responsabilidade Social Empresarial. Divulgação científica e tecnológica do IFPA N¹9, 82-98.

Ashmos, D., \& Duchon, D. (2000). Spirituality at work: conceptualization and measure. Jounal of management inquiry, 2(9). 134-145. https://doi.org/10.1177/105649260092008

Barreto, T. F., Thompson, A. C., \& Feitosa, M. G. ( 2011). Espiritualidade no ambiente de trabalho - revisão dos conceitos, dimensões e críticas. Belo horizonte. 1-14. http://www.abepro.org.br/biblioteca/enegep2011_tn_sto_145_908_18812.pdf.

Barreto, T. F., Thompson, A. C., \& Feitosa, M. G. (2010). Mapeamento da Produção Acadêmica Nacional em Espiritualidade no Ambiente de Trabalho: O Brasil em Desenvolvimento Tardio?. XIII SEMEAD seminários em administração, 1-15. http://sistema.semead.com.br/13semead/resultado/an_resumo.asp?pagina=222

Bezerra, M. (2006). A relação entre a percepção da espiritualidade na organização e o comprometimento organizacional afetivo, normativo e instrumental: estudo de caso com um grupo de líderes do Banco do Brasil no estado de Pernambuco. Dissertação de Mestrado Profissional em Gestão Empresarial - Faculdade Boa Viagem. Recífe, PE.

Bezerra, M., \& Maria , L. (2007). Espiritualidade nas Organizações e Comprometimento Organizacional. Estudo de Caso. XXXI Encontro da ENANPAD, 1-14. http://www.anpad.org.br/diversos/down_zips/33/GPR-A2284.pdf

Boog, G. G. (2005). Espiritualidade nas empresas. www.xamanismo.com.br/conteudo 465.html.

Costa, C. (2005) Sociologia: Introdução à ciência da sociedade. 3. Ed. São Paulo: Moderna.

Enes, R., \& Costa, S. (2015). Uma análise da qualidade de vida no ambiente de trabalho por meio da espiritualidade coporativa. Xi congresso de exelência em gestão. https://app.uff.br/riuff/handle/1/20801

Fernández, B. (2016). La empresa un organismo vivo.

Ferreira, A. (2014). Novo dicionário eletrônico aurélio versão 5.0. (3). Positivo informática Itda.

Garcia, F. (2013). O impacto da espiritualidade no trabalho e de percepção de saúde organizacional sobre comportamento de cidadania organzacional. http://tede.metodista.br/jspui/handle/tede/49 .

Gardner, H. (1999). Inteligencias múltiples: la teoria en la practica. Barcelona: Paidós. 
Krishnakumar, S., \& Neck, C. (2002). The what, why and how of spirituality in the workplace. $\begin{array}{llll}\text { Journal of Managerial 153-164. } & \text { Psychology, }\end{array}$ https://doi.org/10.1108/02683940210423060

Lakatos, M.; Andrade, M. (2010) Fundamentos de metodologia cientifica. 7. Ed. São Paulo: Atlas Editora.

Kerber, R. (2009). Espiritualidade nas Empresas : Uma possibilidade de Humanização do Trabalho. 2. ed. Porto Alegre.

Layrargues, P. (1998). Cortina de Fumaça o discurso empresarial verde e a ideologia da racionalidade econômica. São Paulo, SP, Brasil: Annablume.

Menegat, J., Sarmento, D. F., \& Díaz, M. (2014). Bem-estar no ambiente de trabalho: a espiritualidade como diferencial. Revista conhecimento e diversidade, 6(12), 129-144. https://revistas.unilasalle.edu.br/index.php/conhecimento_diversidade/article/view/1779

Neal, C. (1999). A concious change in the workplace. Th jornal of qualiy and participation, 22(2), https://search.proquest.com/openview/b3351894eed4f2b64706fd3a440a507a

Pereira, F. C., \& Borges, M. E. (2006). A inteligência empresarial e a biologia do conhecer: uma análise exploratório-qualitativa do setor de pequenas e médias empresas de consultoria de belo horizonte. Revista eletrônica De Biblioteconomia E Ciência Da informação, 11(22), 38-52. https://doi.org/10.5007/1518-2924.2006v11n22p38.

Rabello, M. D. (2008). Inteligência Espitual. Tatui-SP: Casa Publicadora Brasileira.

Rego, A., Cunha, M. P., \& Souto, S. (2007). Espiritualidade nas organizações e comprometimento. RAE-eletrônica, 6(2).1-27. https://doi.org/10.1590/S167656482007000200003

Ribeiro, P. M. (2012). O papel das redes sociais no crescimento empresarial [Universidad de Minho]. http://hdl.handle.net/1822/24806

Roselló, F. T. (2012). Inteligência Espiritual. Barcelona: Plataforma editorial.

Senge, P. M. (2009). A quinta disciplina: a arte e prática da organização que aprende (Edição revisada e ampliada ed.). (G. Z. Neto, Trad.) Rio de Janeiro, RJ: Best Seller.

Tecchio, E. (2015). A influência da espiritualidade no processo de gestão do conhecimento em empresas de base tecnológica [Universidade Federal de Santa Catarina]. https://repositorio.ufsc.br/xmlui/handle/123456789/135510.

Vaticano (2006) $(25$ de março de 2006). Fonte: Vaticano: http://www.vatican/holy_father/paual_ii/homilies/1979/documents/hf_iphom_19790405_univ-roma_po.html

Vergara, S. C., \& Moura, L. S. (2012). Práticas de espiritualidade na gestão de pessoas. Negócios e Talentos, 7(7), 51-74. 
Woods, J. A., \& Cortada, J. (2000). The knowledge menegement yearbook 200-2001. Estados Unidos da América: Butterworth-Heinermenn.

Zohar, D., \& Marshall, I. (2002). QS: inteligência espiritual (2 ed.). Rio de Janeiro: Record. 